\title{
Large-Eddy Simulation of Cavitating Tip Leakage Vortex Structures and Dynamics around a NACA0009 Hydrofoil
}

\author{
Linlin Geng ${ }^{1}$, Desheng Zhang ${ }^{1, *}$, Jian Chen ${ }^{1,2}$ and Xavier Escaler ${ }^{2} \mathbb{D}$ \\ 1 Research Center of Fluid Machinery Engineering and Technology, Jiangsu University, \\ Zhenjiang 212013, China; linlin.geng@ujs.edu.cn (L.G.); Jianchenujs@outlook.com (J.C.) \\ 2 Department of Fluid Mechanics, Universitat Politècnica de Catalunya, Av. Diagonal 647, \\ 08028 Barcelona, Spain; xavier.escaler@upc.edu \\ * Correspondence: zds@ujs.edu.cn
}

Citation: Geng, L.; Zhang, D.; Chen, J.; Escaler, X. Large-Eddy Simulation of Cavitating Tip Leakage Vortex Structures and Dynamics around a NACA0009 Hydrofoil. J. Mar. Sci. Eng. 2021, 9, 1198. https://doi.org/ 10.3390/jmse9111198

Academic Editor:

Unai Fernandez-Gamiz

Received: 28 September 2021

Accepted: 23 October 2021

Published: 30 October 2021

Publisher's Note: MDPI stays neutral with regard to jurisdictional claims in published maps and institutional affiliations.

Copyright: (C) 2021 by the authors. Licensee MDPI, Basel, Switzerland. This article is an open access article distributed under the terms and conditions of the Creative Commons Attribution (CC BY) license (https:// creativecommons.org/licenses/by/ $4.0 /)$.

\begin{abstract}
The tip leakage vortex (TLV) has aroused great concern for turbomachine performance, stability and noise generation as well as cavitation erosion. To better understand structures and dynamics of the TLV, large-eddy simulation (LES) is coupled with a homogeneous cavitation model to simulate the cavitation flow around a NACA0009 hydrofoil with a given clearance. The numerical results are validated by comparisons with experimental measurements. The results demonstrate that the present LES can well predict the mean behavior of the TLV. By visualizing the mean streamlines and mean streamwise vorticity, it shows that the TLV dominates the end-wall vortex structures, and that the generation and evolution of the other vortices are found to be closely related to the development of the TLV. In addition, as the TLV moves downstream, it undergoes an interesting progression, i.e., the vortex core radius keeps increasing and the axial velocity of vortex center experiences a conversion from jet-like profile to wake-like profile.
\end{abstract}

Keywords: tip leakage vortex; large-eddy simulation; vortex structures; vortex core; axial velocity

\section{Introduction}

The existence of clearance between impeller tip and casing wall in a turbomachine is inevitable for its operation. However, this tip clearance is the major source of tip leakage flow, the production of complicated tip vortices, and turbulent flow. These tip vortices, especially the tip leakage vortex (TLV), may cause significant adverse effects in practical engineering problems. For example, the generation of strong turbulent flow in the tip region results in efficiency losses [1], the propeller tip vortex cavitation on a submerged submarine causes undesirable noise and vibration [2], and the tip vortex often induces blockage and rotating instabilities in the flow passage in an axial compressor [3-5].

Over recent decades, a large number of experimental and numerical investigations of the TLV have been conducted. With regard to the experimental investigations, the tip leakage flow and its subsequent rolling up into a TLV were clearly demonstrated and described originally by Rains [6], in which an assumption was proposed that the tip leakage flow could be simulated by a two-dimensional (2-D) unsteady crossflow. Lakshminarayana et al. $[7,8]$ used a triaxial hot-wire probe rotating with the rotor to determine the flow field and turbulence properties in the end-wall region of an axial compressor rotor. They found that the leakage flow starts beyond a quarter-chord and tends to roll up further away from the suction surface, and that all the components of turbulent intensities and stresses are high in the leakage flow mixing region. Storer and Cumpsty [9] experimentally studied the tip leakage flow in a linear cascade with tip gaps of $2 \%$ and $4 \%$ of the chord. They concluded that the distribution of the tip leakage flow is controlled by the static pressure distributions at the blade tip, and that the formation of the TLV affects the distribution of pressure near the blade tip. Kang and Hirsch [10-12] measured the three-dimensional (3-D) flow in a linear compressor cascade tunnel with different tip 
clearance using surface flow visualization and a five-hole probe, and observed a multiple tip vortex structure (TLV, tip separation vortex, passage vortex and secondary vortex). More recently, Wu et al. [13-15] captured the structure of TLV and turbulence in an axial water-jet pump with Stereo Particle Image Velocimetry (SPIV) technology. The SPIV results showed that the instantaneous TLV structure is composed of a train of vortex filaments, and that turbulence in the TLV is anisotropic and spatially non-uniform.

In addition to the experimental measurements, numerical simulation has proved to be a reliable approach to study the tip leakage flow. Storer and Cumpsty [16] conducted RANS calculations and showed that the principal mechanism of loss creation due to tip leakage flow is the mixing of passage and leakage flows. Shin [17] and Khorrami et al. [18] performed RANS computations to predict the flow field in a low-speed linear compressor cascade with stationary end-wall. The numerical results agreed favorably with experimental data. You et al. $[19,20]$ applied LES to analyze the vorticity and turbulent kinetic energy production mechanisms, and examined the influence of rotor blade geometry on the structure of the TLV. Recently, Gaggero et al. [21] demonstrated the capability of multiphase RANS computations (realizable $k-\varepsilon$ approach in conjunction with the Schnerr-Sauer cavitation model) to correctly predict the tip cavitation and tip leakage vortex cavitation in the propeller. Zhang et al. [21,22] investigated the trajectory and unsteady cavitation of TLV in an axial flow pump employing the shear-stress transport turbulence model combined with a homogeneous cavitation model.

The aforementioned experimental and numerical studies have focused on the tip leakage flow in axial turbomachines. However, to the author's knowledge, there is little information [23-25] regarding the study of the cavitating TLV around a hydrofoil. Moreover, because of some limitations of experimental measurements and inherent assumptions for the RANS model, we conducted this study by performing LES in conjunction with a homogeneous cavitation model. The specific objectives of this study are to investigate the TLV in a configuration matched by Dreyer et al. [25] to gain a better understanding of cavitating TLV around a NACA0009 hydrofoil, and to obtain insight into the evolution of the internal structure of the TLV and associated dynamic characteristics in the whole flow field by examining vortex strength, velocity and pressure distributions, vortex core radius and the changes in axial velocity.

\section{Mathematical Model and Numerical Method}

\subsection{Physical Cavitation Model}

The cavitation model used in this study is based on Zwart et al. [26], in which the liquid-vapor mass transfer (evaporation and condensation) is governed by the following equations:

$$
\frac{\partial\left(\alpha_{v} \rho_{v}\right)}{\partial t}+\frac{\partial\left(\alpha_{v} \rho_{v} u_{j}\right)}{\partial x_{j}}=R_{e}-R_{c}
$$

where $\alpha_{v}$ is the vapor volume fraction, $\rho_{v}$ is the vapor density, $u_{j}$ is velocity in tensor form, $x_{j}$ is Cartesian coordinates, and $t$ is time. The terms of $R_{e}$ and $R_{c}$ account for the mass transfer between the liquid and vapor phases in cavitation and are modeled based on the Rayleigh-Plesset equation. These two terms are defined as:

$$
\begin{gathered}
R_{e}=F_{v a p} \frac{3 \alpha_{n u c}\left(1-\alpha_{v}\right) \rho_{v}}{R_{B}} \sqrt{\frac{2}{3} \frac{P_{v}-P}{\rho_{l}}}\left(P \leq P_{v}\right) \\
R_{c}=F_{\text {cond }} \frac{3 \alpha_{v} \rho_{v}}{R_{B}} \sqrt{\frac{2}{3} \frac{P-P_{v}}{\rho_{l}}}\left(P \leq P_{v}\right)
\end{gathered}
$$

where $\rho_{l}$ is the liquid density, $R_{B}$ is the bubble radius, $\alpha_{n u c}$ is the nucleation site volume fraction, $P_{v}$ is the saturated liquid vapor pressure, which is set to be $3574 P a, P$ is the local fluid pressure, and $F_{\text {vap }}$ and $F_{\text {cond }}$ are the empirical coefficients for vaporization and condensation process, respectively. In this work, the assumed model constants are 
$R_{B}=10^{-6} \mathrm{~m}, \alpha_{\text {nuc }}=0.0005, F_{\text {vap }}=50$, and $F_{\text {cond }}=0.01$ based on the work by Zwart et al. [26], which were validated in various studies $[27,28]$.

\subsection{Governing Equations and the LES Approach}

Based on the assumption of the mixture of vapor and liquid in a cavitation flow having the same velocity and pressure, the governing equation consists of the mass and momentum conservation equation as follows:

$$
\left\{\begin{array}{l}
\frac{\partial \rho_{m}}{\partial t}+\frac{\partial\left(\rho_{m} u_{j}\right)}{\partial x_{j}}=0 \\
\frac{\partial\left(\rho_{m} u_{i}\right)}{\partial t}+\frac{\partial\left(\rho_{m} u_{i} u_{j}\right)}{\partial x_{j}}=-\frac{\partial P}{\partial x_{i}}+\frac{\partial}{\partial x_{i}}\left(\mu_{m} \frac{\partial u_{i}}{\partial x_{j}}\right)
\end{array}\right.
$$

where $u_{i}$ is velocity in tensor form. The dynamic viscosity $\mu_{m}$ and the mixture density $\rho_{m}$ are defined as:

$$
\begin{aligned}
& \mu_{m}=\alpha_{v} \mu_{v}+\left(1-\alpha_{v}\right) \mu_{l} \\
& \rho_{m}=\alpha_{v} \rho_{v}+\left(1-\alpha_{v}\right) \rho_{l}
\end{aligned}
$$

The LES is an approach which filters the equations of movement and decomposition of the flow variables into a large scale (resolved) and a small scale (unresolved) at the grid level. The filtered velocity filed $\overline{u_{i}}$ is computed by the following equation:

$$
\left\{\begin{array}{l}
\frac{\partial \rho_{m}}{\partial t}+\frac{\partial\left(\rho_{m} \bar{u}_{j}\right)}{\partial x_{j}}=0 \\
\frac{\partial\left(\rho_{m} \bar{u}_{i}\right)}{\partial t}+\frac{\partial\left(\rho_{m} \bar{u}_{i} \bar{u}_{j}\right)}{\partial x_{j}}=-\frac{\partial \bar{P}}{\partial x_{i}}+\frac{\partial}{\partial x_{i}}\left(\mu_{m} \frac{\partial \bar{u}_{i}}{\partial x_{j}}\right)-\frac{\partial \tau_{i j}}{\partial x_{i}}
\end{array}\right.
$$

where $\tau_{i j}$ denotes the SGS stress, which includes the small scale effect and is defined by:

$$
\tau_{i j}=\rho_{m}\left(\overline{u_{i} u_{j}}-\bar{u}_{i} \bar{u}_{j}\right)
$$

One commonly used SGS model is an eddy-viscosity approach which relates $\tau_{i j}$ to $\overline{S_{i j}}$ in the following way:

$$
-\left(\tau_{i j}-\frac{\delta_{i j}}{3} \tau_{k k}\right)=2 v_{s g s} \overline{S_{i j}}
$$

where $\overline{S_{i j}}$ is the large scale strain rate tensor, and $v_{s g s}$ is the eddy viscosity. In the dynamic Smagorinsky-Lilly model $[29,30], v_{s g s}$ is computed as:

$$
v_{s g s}=C_{d} \Delta^{2}\left|\overline{S_{i j}}\right|
$$

where $C_{d}$ is the model coefficient obtained from the dynamic Smagorinsky-Lilly model in time and space over a fairly wide range, and $\Delta$ is the local grid size defined as:

$$
\Delta=(\Delta x \cdot \Delta y \cdot \Delta z)^{1 / 3}
$$

where $\Delta x, \Delta y$, and $\Delta z$ are the mesh sizes.

\subsection{Hydrofoil Model and Setup}

The present study focuses on a NACA0009 hydrofoil with an original chord of $c_{0}=110 \mathrm{~mm}$ and a span of $150 \mathrm{~mm}$, following the experimental setup of Dreyer et al. [25]. In the experiment, the hydrofoil truncated at $c=100 \mathrm{~mm}$ was mounted on a sliding support allowing an adjustable clearance between 0 and $20 \mathrm{~mm}$. In addition, five incidence angles $\left(3^{\circ}, 5^{\circ}, 7^{\circ}, 10^{\circ}, 12^{\circ}\right)$ were tested in combination with four inflow velocities $(5,10,15$, and $20 \mathrm{~m} / \mathrm{s}$ ). It should be noted that only one of the experimental configurations was carried out in the current LES research. 
The flow configuration and the coordinate system are schematically shown in Figure 1. The computational domain, which extends two chords upstream from the leading edge and 4.5 chords downstream from the trailing edge, has dimensions of $L_{x} \times L_{y} \times L_{z}=7.5 c \times 1.5 c \times 1.5 c$, in which the subscript $x, y$ and $z$ represent spanwise, pitchwise and streamwise coordinates, respectively. The other important physical parameters for this simulation are as follows: the blade span is $s=1.48 c$, the size of the tip gap is $\tau=0.02 c$, and the incidence angle is $10^{\circ}$. The boundary conditions are specified according to the experimental setup, and the inflow velocity, which will be a reference velocity to normalize the velocity variables, is fixed at $V_{\infty}=10 \mathrm{~m} / \mathrm{s}$ with a turbulent intensity set at $1 \%$. The corresponding Reynolds number is $1,120,000$ based on the chord $(c)$ and the inflow velocity $\left(V_{\infty}\right)$. A uniform outlet pressure is specified as $P_{\text {outlet }}=1$ bar, and the corresponding cavitation number is 1.93 computed by $\sigma=\left(P_{\text {outlet }}-P_{v}\right) / 0.5 \rho_{l} V_{\infty}^{2}$. A no-slip boundary condition is set for the hydrofoil surface, and wall conditions are set for the boundaries of the tunnel.

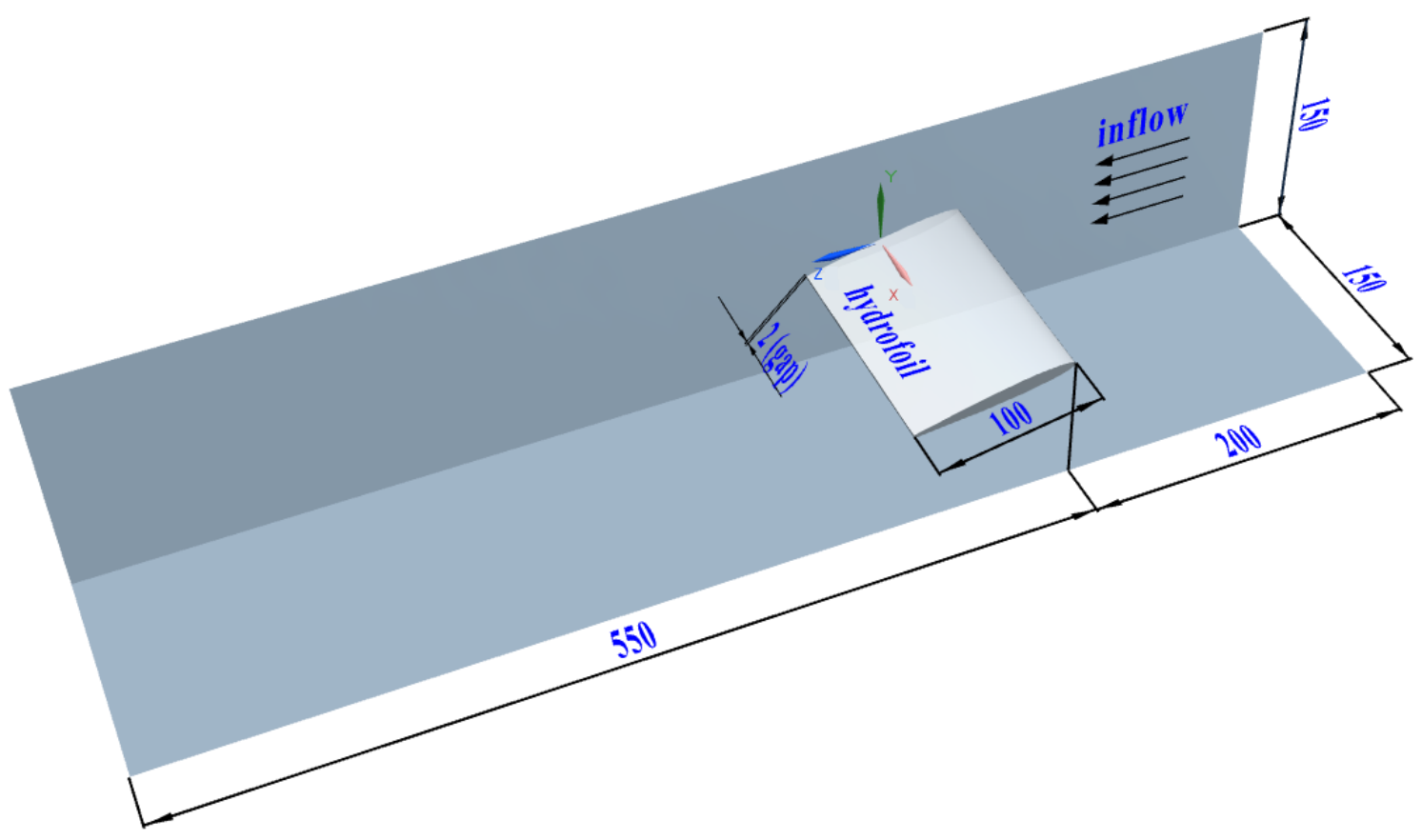

Figure 1. Computational domain with Cartesian coordinates.

\subsection{Grid Spacing and Resolution}

The mesh size is of extreme importance to ensure the validity of the LES computation because the LES approach filters the equations of momentum and decomposition of the flow variables into a large scale (resolved) and a small scale (unresolved) at the grid level. It is recommended that the mesh size in the region of primary interest should be located in the inertial subrange to resolve approximately $80 \%$ of the energy directly according to Pope's theory [31]. Namely, the ratio of the grid size $\Delta$ to the lengthscale $l_{E I}$ should be less than 1.0, in which the lengthscale $l_{E I}$ is defined as the demarcation between the anisotropic large eddies $\left(l>l_{E I}\right)$ and the isotropic small eddies $\left(l<l_{E I}\right)$ according to Kolmogorov's hypothesis. The distribution of $l_{E I}$ can be obtained by the following equations:

$$
l_{E I}=\frac{1}{6} L_{11}
$$

where $L_{11}$ is the integral length scale, and its ratio to the lengthscale of the energycontaining eddies $\left(L=k^{1.5} / \varepsilon\right)$ is a function of $R_{\lambda}$ as shown in Figure 2, and $R_{\lambda}$ is defined as:

$$
R_{\lambda}=\left(\frac{20}{3} \operatorname{Re}_{L}\right)^{1 / 2}=\left(\frac{20}{3} \frac{k^{2}}{\varepsilon v}\right)^{1 / 2}
$$


where $R e_{L}$ is the turbulence Reynolds number defined by $R e_{L}=k^{2} / \varepsilon v, k$ is the local turbulent kinetic energy, $\varepsilon$ is the local rate of turbulent energy dissipation, and $v$ is the kinematic viscosity.

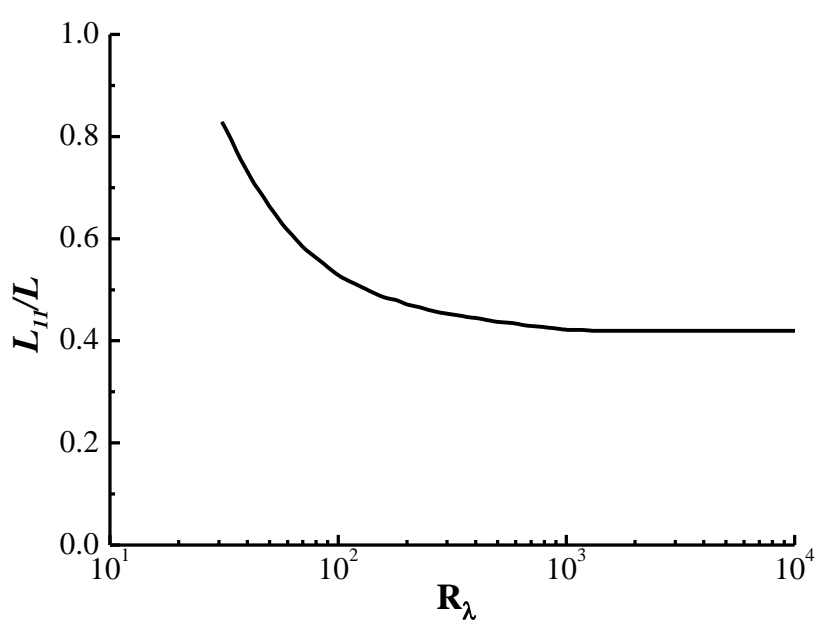

Figure 2. The ratio of the integral lengthscale $L_{11}$ to $L$ as a function of the Reynolds number for the model spectrum.

To obtain the ratio of $\Delta / l_{E I}$, the spatial distribution of the lengthscale $l_{E I}$ or, equivalently, the distributions of total kinetic energy and dissipation are required. Consequently, before performing the LES, a RANS calculation should be carried out to determine the distributions of the kinetic energy and dissipation based on a relatively coarse mesh, which then serves as a guide for the mesh size in the region of primary interest. Then the LES is conducted with the modified mesh size until it satisfies the standard $\left(\Delta / l_{E I} \leq 1\right)$.

Based on the above method, and considering a compromise between calculation accuracy and computational time, the final ratio of the grid size $\Delta$ to the lengthscale $l_{E I}$ is shown in a $x-y$ plane at $z / c=0.3$ where a variety of vortex structures are fully developed (Figure 3). This shows that the present LES is capable of resolving $80 \%$ of the energy at least in the region of primary interest $(x / c<0.1)$.

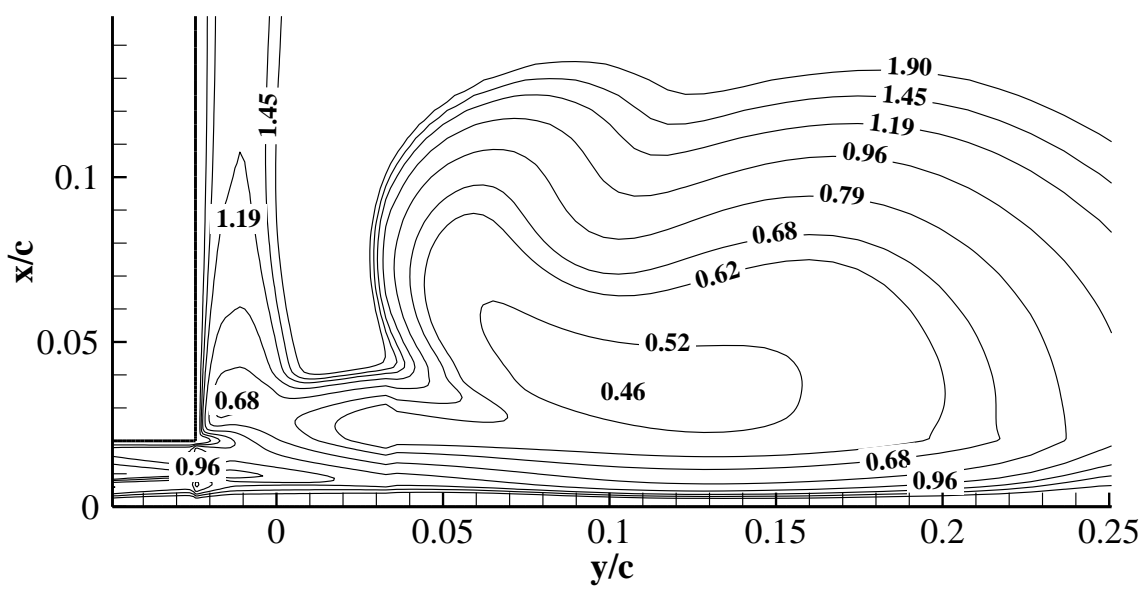

Figure 3. The ratio of the grid size $\Delta$ to the lengthscale $l_{E I}$ at at $z / c=0.3$.

The mesh size used for the present study is $150 \times 255 \times 300$. As shown in Figure 4, the meshes are clustered around the tip gap, blade pressure and suction surfaces, and end-wall to ensure appropriate resolution in the region of primary interest. There are 31 mesh points allocated across the tip-gap region for with a tip-gap size of $0.02 c$. Based on the chord in the spanwise, pitchwise, and streamwise directions, the grid spacings are 
$6.7 \times 10^{-4} \leq \Delta x / c \leq 5.5 \times 10^{-2}, 5 \times 10^{-4} \leq \Delta y / c \leq 5 \times 10^{-2}$, and $5.8 \times 10^{-3} \leq \Delta z / c \leq$ $6.5 \times 10^{-2}$, respectively. The growth factor of the mesh around the tip-gap and blade surface is limited to a range of 1.0 1.2. The values of $y^{+}$varies due to different velocity magnitude, ranging from 0.3 to 19 with an average value of 3.4.

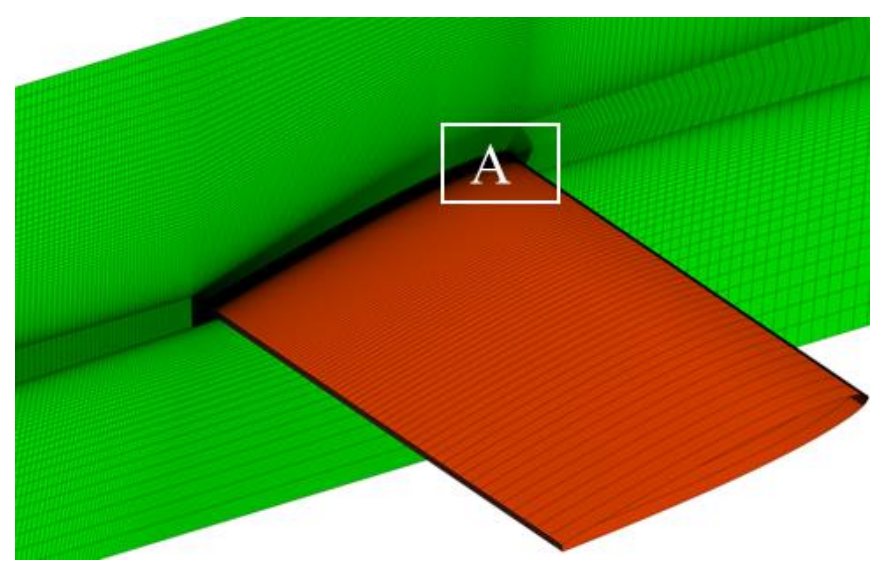

(a)

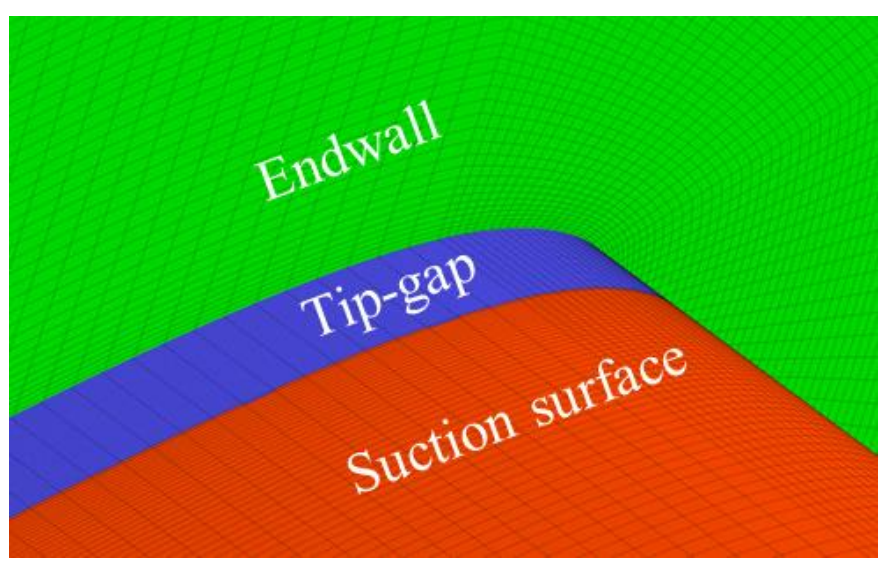

(b)

Figure 4. Meshing computational domain: (a) global mesh, and (b) local region A.

The LES was performed using commercial software ANSYS CFX. The time-dependent governing equations are discretized in both space and time domains and solved with a pressure-velocity coupling method using a finite volume method. A non-dissipative central-difference is used for spatial-discretization on a fine structure grid, which has been certified to be crucial for retaining the accuracy and predictive capability of the LES method [32-34]. For the transient terms, an implicit second-order Backward Euler scheme is used, which is recommended by ANSYS CFX. There are about 10 internal iterations to accomplish the convergence criterion $\left(1 \times 10^{-6}\right)$ for a constant time step of $5 \times 10^{-6} \mathrm{~s}$. The corresponding non-dimensional time step based on the inflow velocity and the minimum mesh size $\left(5 \times 10^{-5} \mathrm{~m}\right)$ is 1 , which ensures an average Courand-Friedrichs-Lewy number less than 1.0. In addition, the initial condition is specified by interpolating the velocity profile extracted from the RANS computations.

\section{Results and Discussion}

\subsection{Validation of the LES}

To check whether the LES is able to capture the accurate flow information and analyze the tip leakage vortex structures and dynamics characteristics, the present LES was validated against the experimental data. It should be noted that the foil tip pressure side corner was rounded with a small radius of $1 \mathrm{~mm}$ in the experiment, which was not considered in the present LES.

Figure 5a shows the cavitation patterns in the whole computational domain defined by the vapor fraction iso-surface of $\alpha_{v}=0.1$ [22], and Figure $5 \mathrm{~b}$ represents experimental cavitation patterns used to visualize the TLV trajectory. The qualitative comparison shows that the various cavitation patterns including the TLV cavitation, clearance cavitation and blade surface cavitation (behind in the TLV cavitation) in the experiment are also shown by the LES. However, the TLV cavitation appears almost along the whole chord in the experiment, while the iso-surface of vapor fraction only extends to $65 \%$ of the chord, which indicates that the TLV cavitation is underestimated by the present LES. On the contrary, the clearance cavitation predicted by the present LES is more intense than in the experiment. These differences are attributed to the influence of the rounded pressure edge which has an impact on the trajectory and the strength of the TLV [35], and contributes to reducing the clearance cavitation [36]. 


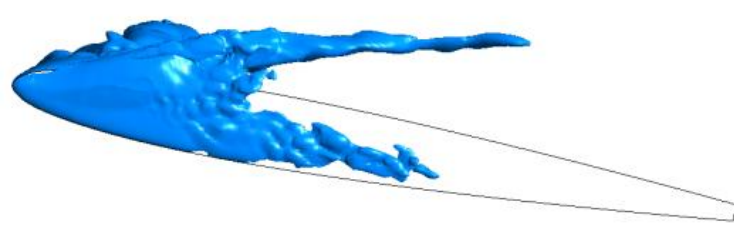

(a)

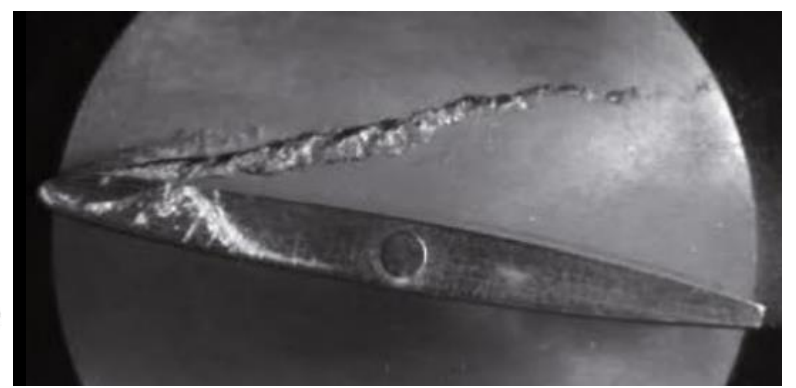

(b)

Figure 5. Qualitative comparison of cavitation patterns: (a) vapor fraction iso-surface of $\alpha_{v}=0.1$ predicted by the present LES, and (b) cavitation in the experiment.

The quantitative comparisons between experimental data [37] and present LES results are presented in Figures 6-8. Figure 6 shows the comparison of the TLV trajectories in the part of the flow field. Figure 7 shows the comparison of iso-lines of non-dimensional different streamwise vorticity calculated by $\omega_{z}^{*}=\left(\omega_{z} c\right) / V_{\infty}$. Figure 8 shows the comparison of contours of each velocity component at $x / c=1.0$.

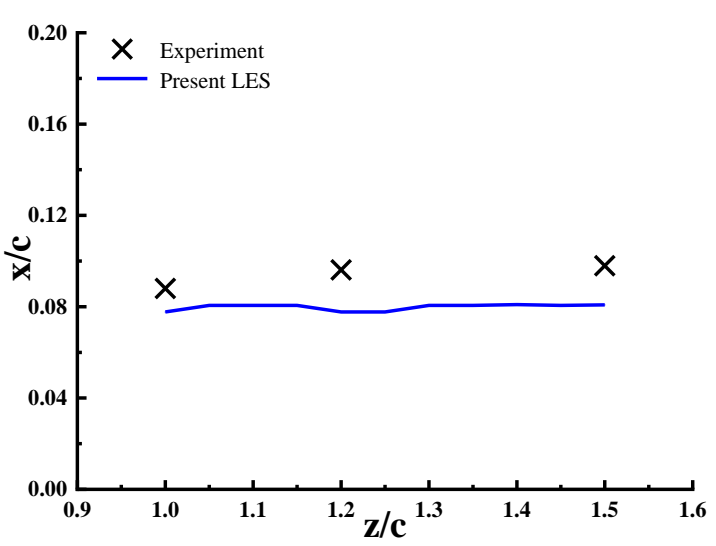

(a)

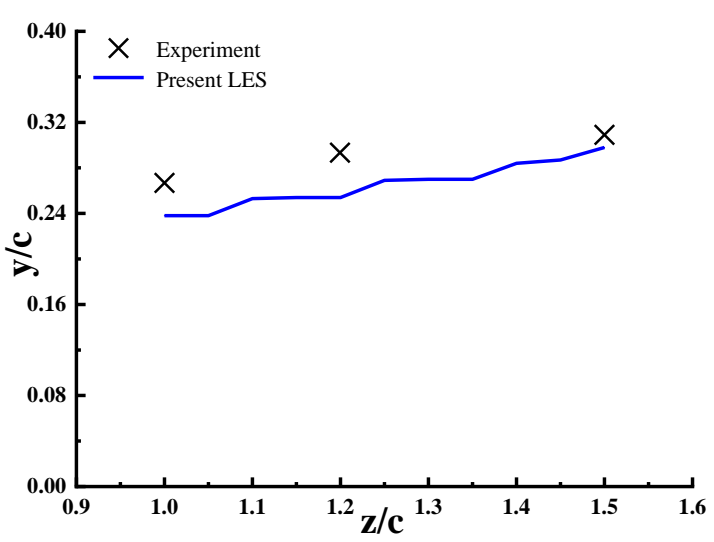

(b)

Figure 6. Comparison of trajectories of TLV: (a) spanwise, and (b) pitchwise.

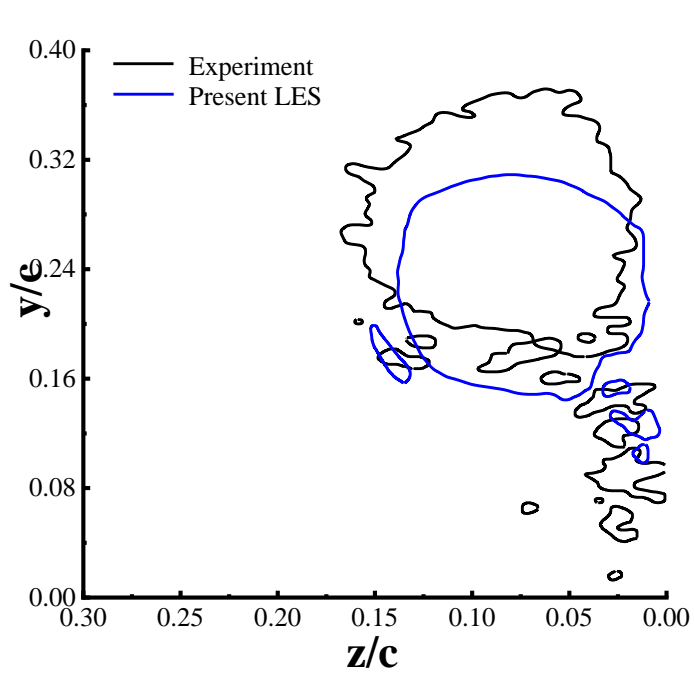

(a)

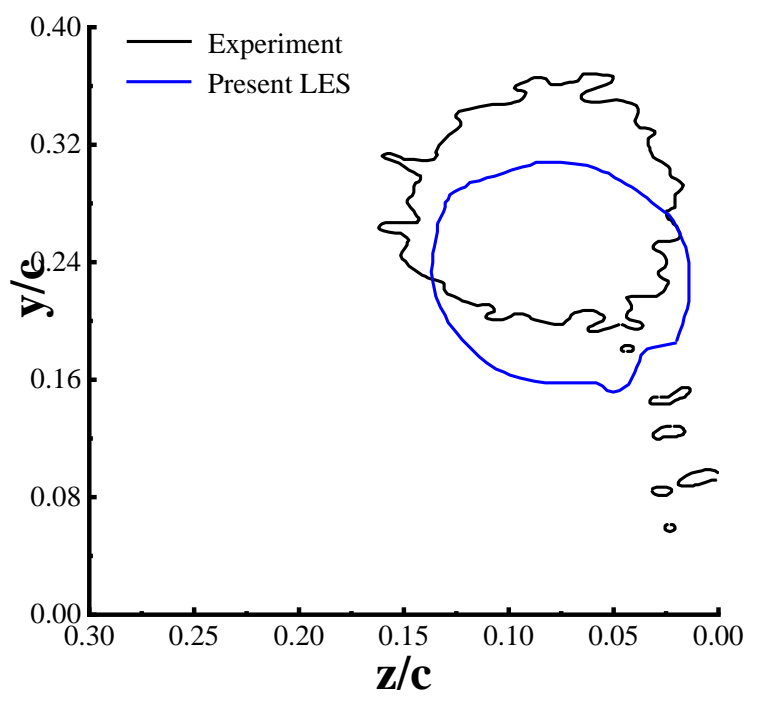

(b)

Figure 7. Comparison of iso-lines of the non-dimensional streamwise vorticity: (a) $\omega_{z}^{*}=-2$, and (b) $\omega_{z}^{*}=-3$. 
As shown in Figure 6, the trajectories of TLV were generated by each vortex center defined as the point of maximum streamwise vorticity [18,37]. For the spanwise position (Figure 6a), the present computational TLV trajectory shows that TLV evolves closer to the endwall than the experiment. For the pitchwise position (Figure 6b), it is apparent that the trend of TLV evolution is well described by the present LES.

In Figure 7, it should be noted that the negative magnitude of streamwise vorticity predicted by present LES corresponds to the positive one in the experiment due to the opposite definition of streamwise direction. Figure 7a shows that the present computational results not only exhibit the profile of TLV fairly well, but also predict a high level of vorticity located around the TLV and near the endwall in the experiment. Figure $7 \mathrm{~b}$ shows that the present LES can also predict the higher vorticity region well. Under both conditions, the iso-lines predicted by the present LES are quite reasonable in size and profile compared with the experimental measurements.
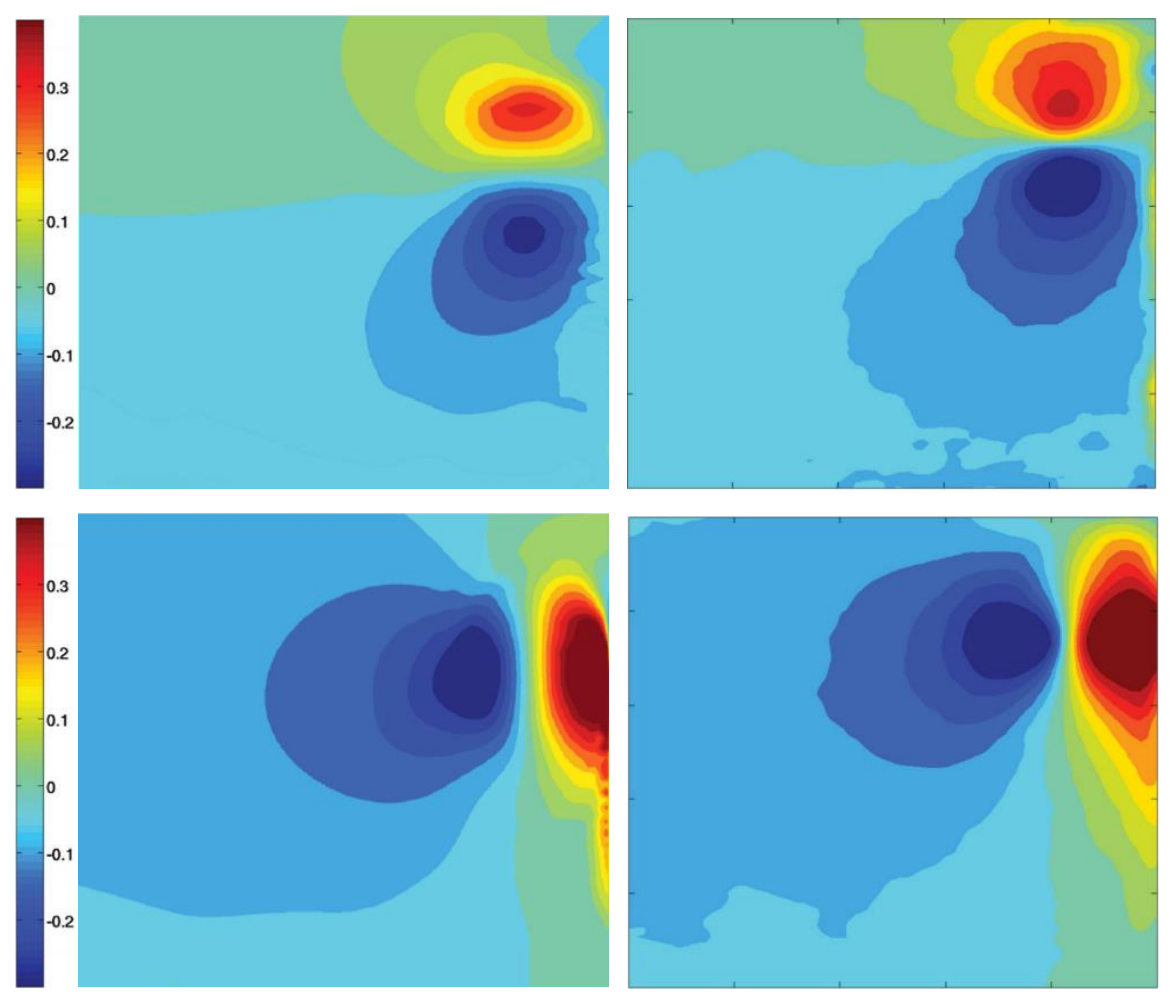

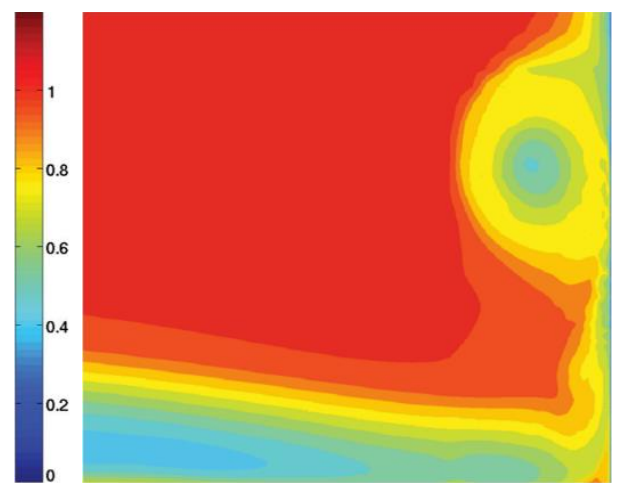

(a)

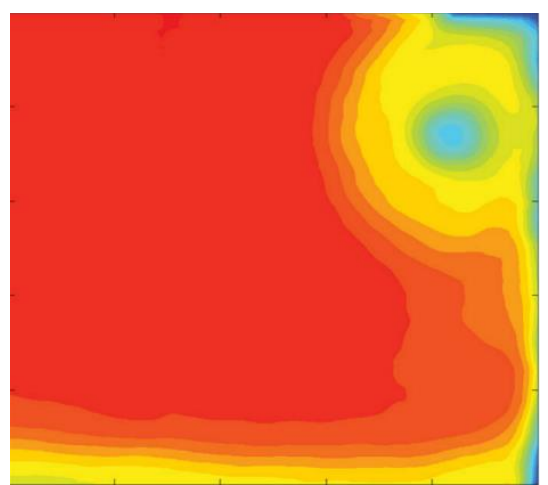

(b)

Figure 8. Comparison of contours of velocity components at $x / c=1.0$ : top: $v_{x}$, middle: $v_{y}$, and bottom: $v_{z}$. (a) Present LES. (b) Experiment. 
The top panel of Figure 8 shows that the whole magnitude of spanwise velocity ranging from the minimum to the maximum in the experiment is predicted better by the present LES. However, the pitchwise gradient of the spanwise velocity around the vortex center is spread on a larger band than that in the experiment. Similarly, the pitchwise velocity topology as shown in the middle panel of Figure 8 is again well captured by the present LES, while the spanwise gradient of the pitchwise velocity around the vortex center is not as steep as that in the experiment. Consequently, the strength of the TLV for the present LES is slightly weaker than that in the experiment. As for the streamwise velocity shown in the bottom panel of Figure 8, the velocity profile and the deficit of the streamwise velocity in the vortex center are captured well by the present simulation. However, the magnitude of the streamwise velocity of the hydrofoil wake viewed by on a horizontal region in the present LES is weaker than that in the experiment. Generally, the velocity topology and velocity magnitude predicted by the present computation agree better with the experimental data.

In summary, the present computational results accurately provide mean quantities and reach an adequate level of confidence to systematically analyze the characteristics of the TLV.

\subsection{Development of Vortex Structures}

In this section, mean streamlines were used to visualize the endwall vortex structures and investigate their development at different streamwise locations. To better understand the vortex structures in the endwall region, firstly a schematic was used to show the gross features, as shown in Figure 9. There are three main vortex structures: tip-leakage vortex which dominates the flow in the endwall region, tip separation vortex which is caused by flow separation, and induced vortex. To learn more about the generation and evolution of the endwall vortex structures observed in Figure 10a,c,e,g, the contour plots of the mean non-dimensional streamwise vorticity in the corresponding $x-y$ planes are shown in Figure $10 \mathrm{~b}, \mathrm{~d}, \mathrm{f}, \mathrm{h}$, because the vorticity method makes it easier to clearly identify the vortex strength and its rotational direction which is generally difficult to recognize when only using mean streamlines.

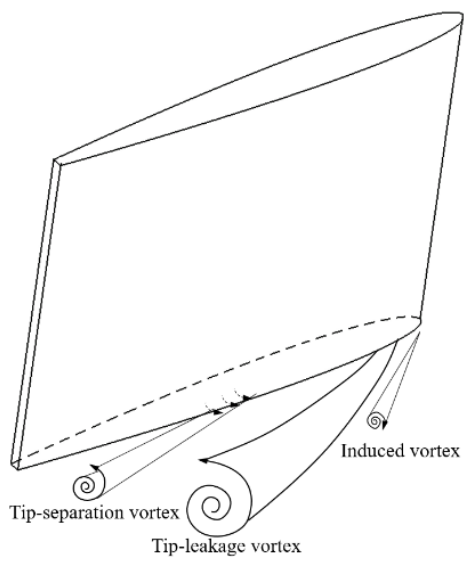

Figure 9. Illustration of the flow structures in the endwall region.

As shown in Figure 10, vortex structures and their strength are completely different at different locations. At $z / c=-0.4$ (Figure 10a,e) which is close to the leading edge, the TLV is clearly captured with a compact structure near the suction side corner and rotates in counter-clockwise direction, and a tip separation vortex is underneath the hydrofoil rotating in the same direction as the TLV. There is also a small secondary vortex located slightly above the TLV near the suction surface, rotating in the opposite direction to the two other vortices, but its strength is relatively weak and it is not observed in any further downstream locations. At $z / c=-0.1$ (Figure 10c,d), the TLV is fully developed and its 
size increases substantially. Additionally, an induced vortex located in the lower-right of the TLV is displayed and rotates in clock-wise direction. At $z / c=0.2$ (Figure 10e,f), the size of the TLV further increases and the core of the main part of the TLV is very well defined but less compact, and its strength is much reduced as displayed in Figure $10 \mathrm{f}$. The induced vortex is no longer as clear as presented in Figure 10c and its strength also decreases suddenly. In addition, the TLV induces a swirling motion beyond its core causing the leakage flow to bend inward and then interact with the tip leakage jet, which generates an array of vortex filaments that rotate in the same direction as the TLV and extend from the suction tip edge to the TLV, as shown in Figure 10e,g. At $z / c=0.4$ (Figure $10 \mathrm{~g}, \mathrm{~h}$ ), the TLV has lost its coherence and broken up, as shown in Figure 10h. The strength of the induced vortex is further reduced even though it is still well shown. Furthermore, there is no merging between the tip separation vortex and the TLV in this configuration.

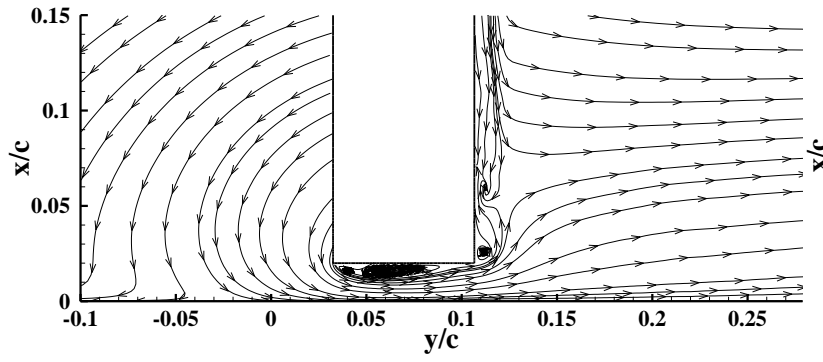

(a)

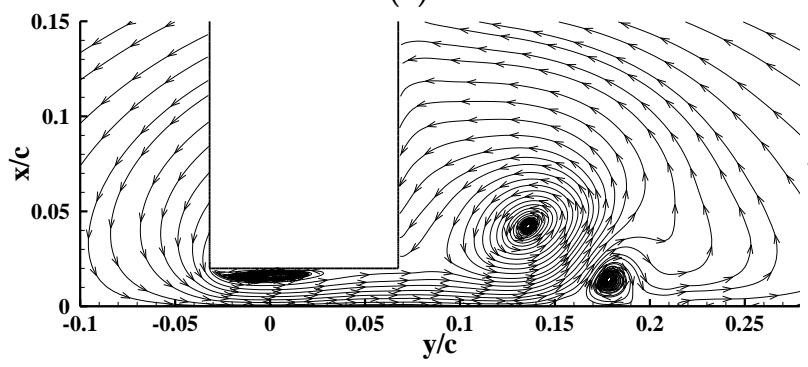

(c)

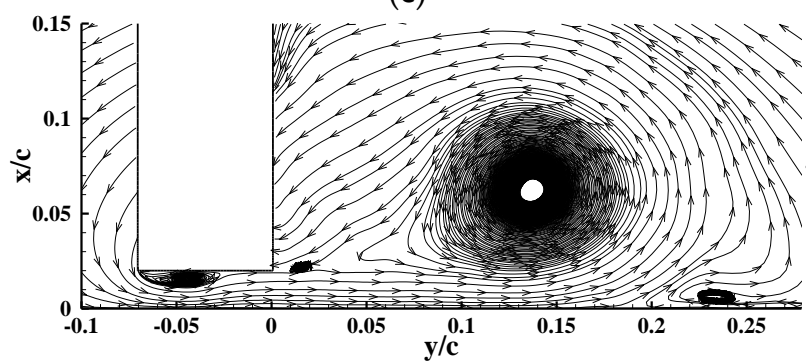

(e)

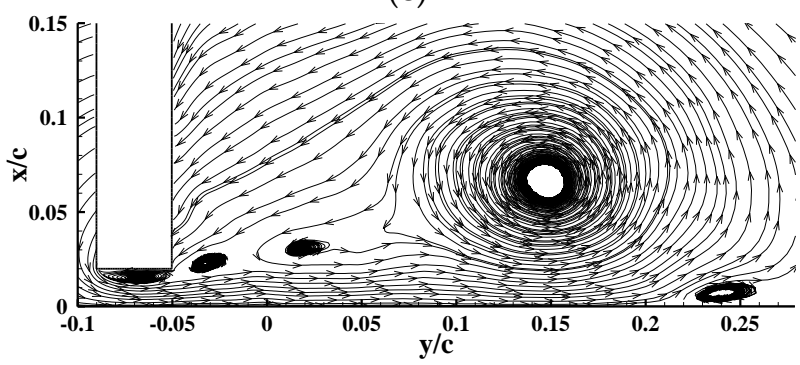

(g)

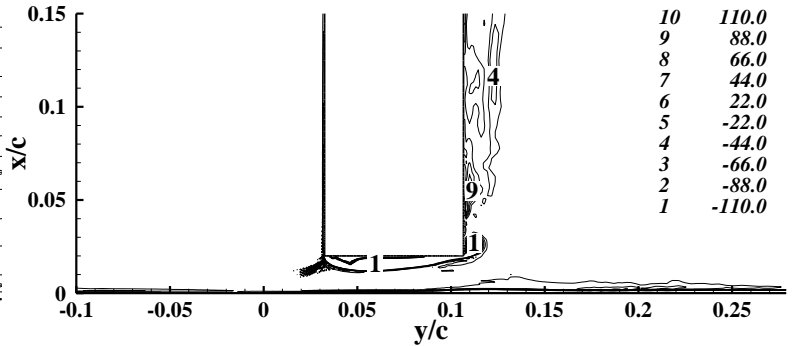

(b)

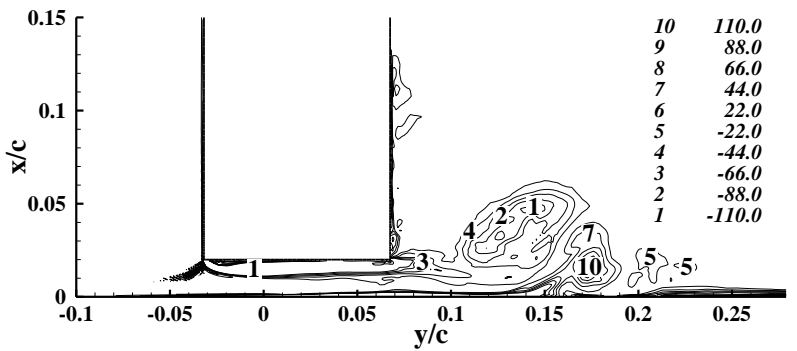

(d)

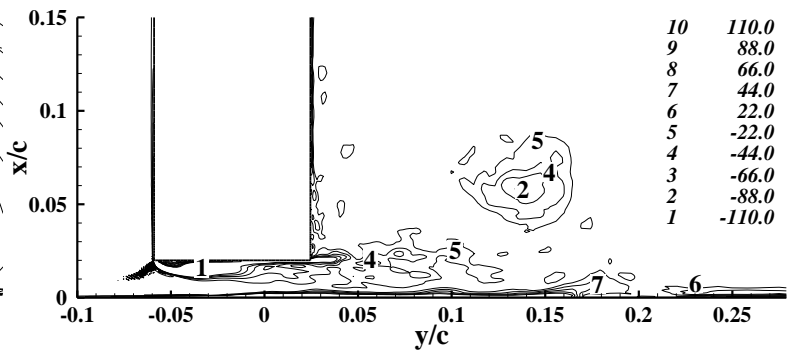

(f)

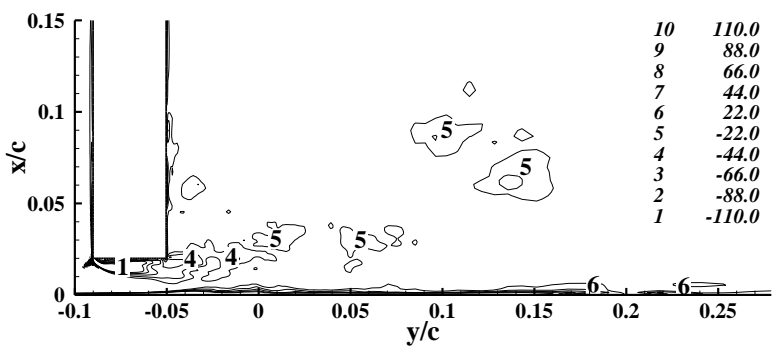

(h)

Figure 10. Mean streamlines and the corresponding contours of non-dimensional mean streamwise vorticity in $x-y$ planes: $(\mathbf{a}, \mathbf{b})$ for $z / c=-0.4,(\mathbf{c}, \mathbf{d})$ for $z / c=-0.1,(\mathbf{e}, \mathbf{f})$ for $z / c=0.2$, and $(\mathbf{g}, \mathbf{h})$ for $z / c=0.4$. 
Another remarkable feature is that the strength of the induced vortex decreases as the strength of the TLV decreases during the evolution of induced vortex (Figure 10c-h). This is because the formation of the induced vortex results from the interaction between the TLV and the wall boundary layer leading to the roll up of a part of the boundary layer [38]. Thus, the higher the strength of the TLV, the easier it is to roll up the boundary layer to form a strong induced vortex.

\subsection{The Production Mechanism of Vorticity}

Figure $11 \mathrm{a}, \mathrm{b}$ illustrate the contour plots of the non-dimensional mean spanwise vorticity $\left(\omega_{z}^{*}\right)$ in $x-y$ planes at two different streamwise locations $(z / c=-0.1$ and $z / c=0.2)$. Figure $11 \mathrm{c}$, d show the pitchwise vorticity $\left(\omega_{y}^{*}\right)$ in corresponding planes. Compared with the corresponding streamwise vorticity shown in Figure $10 \mathrm{~b}, \mathrm{~d}, \mathrm{f}, \mathrm{g}$, it can be seen that the streamwise vorticity component dominates the vorticity field since the strength of streamwise vorticity of the TLV is much bigger than the two other vorticity components in the endwall region. Streamwise vorticity in the TLV is composed of two different velocity derivatives $\left(\omega_{z}=\partial v_{y} / \partial x-\partial v_{y} / \partial x\right)$, i.e., the spanwise derivatives of the pitchwise velocity $\left(\partial v_{y} / \partial x\right)$ and the pitchwise derivatives of the spanwise velocity $\left(\partial v_{y} / \partial x\right)$. However, it is mainly produced by the spanwise derivatives of the pitchwise velocity $\left(\omega_{z} \approx\left(\partial v_{y} / \partial x\right)\right)$ because the mean spanwise velocity is quite small.

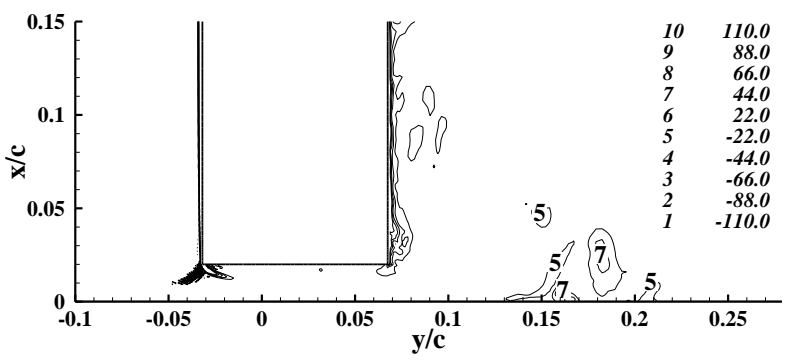

(a)

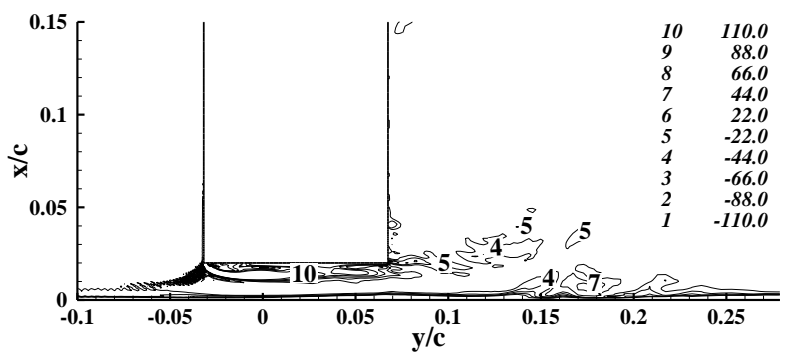

(c)

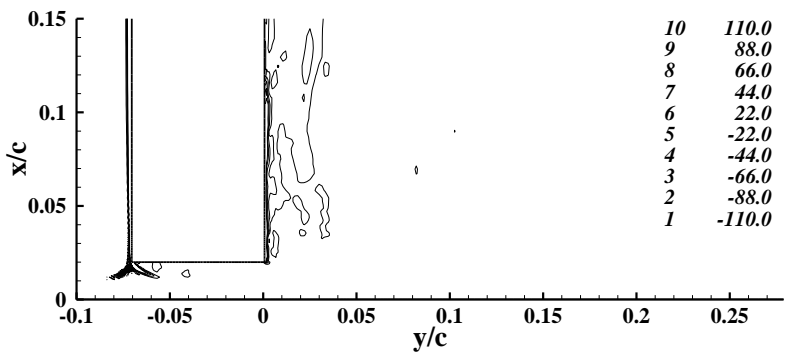

(b)

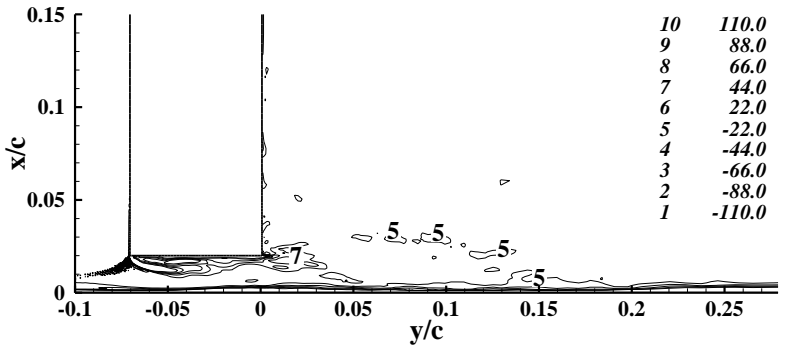

(d)

Figure 11. Contours of non-dimensional mean spanwise (top) and pitchwise (bottom) vorticity components in $x-y$ planes: $(\mathbf{a}, \mathbf{c})$ for $z / c=-0.1$, and $(\mathbf{b}, \mathbf{d})$ for $z / c=0.2$.

Figure 12 shows the mean streamlines and the non-dimensional pitchwise velocity distributions in $y-z$ planes close to the endwall $(x / c=0.01)$ and away from the endwall $(x / c=0.2)$. In Figure $12 \mathrm{a}$, the flow undergoes a sudden change in the pressure side due to the existence of the pressure difference between the pressure side and the suction side, and eventually passes through the tip gap and converges. Because of the turning flow, a positive pitchwise velocity component is produced and its magnitude gradually reduces from the leading edge to the trailing edge in the tip leakage region as can be seen in the contour plot of pitchwise velocity in Figure 12a. While in the plane away from the end-wall (Figure 12b), the streamlines are approximately along the blade surface, and the magnitude of the pitchwise velocity is very small with no clear velocity gradient except in the leading edge region. The abrupt change of the pitchwise velocity along the blade span 
results in large spanwise derivatives of the mean pitchwise velocity $\left(\partial v_{y} / \partial x\right)$, which plays a significant role in generating the strong vorticity of the TLV.

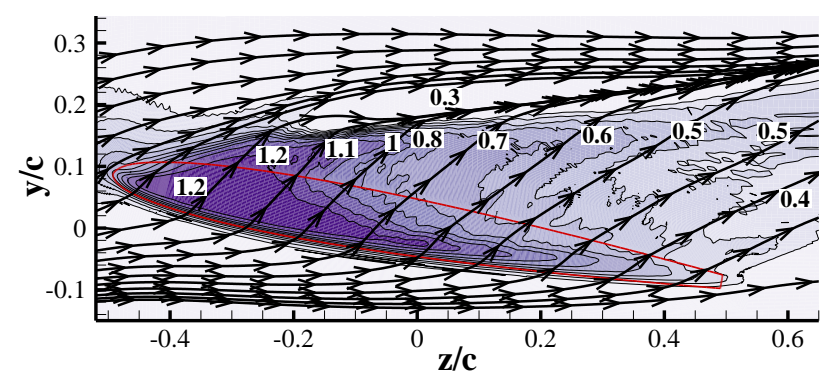

(a)

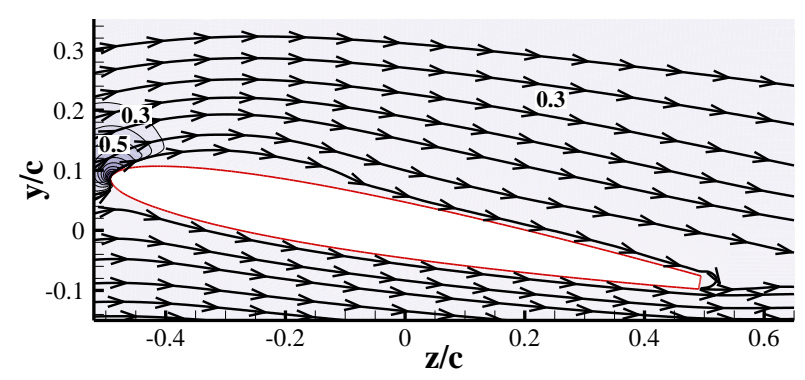

(b)

Figure 12. Pitchwise velocity distributions normalized by the inflow velocity and the streamlines in $\mathrm{y}-\mathrm{z}$ planes: $(\mathbf{a}) x / c=0.01$, and (b) $x / c=0.2$.

\subsection{The TLV Development and Profile Evolution}

In this section, some characteristics of the TLV were obtained by investigating the time averaged profiles of the pitchwise velocity and the axial velocity (i.e., streamwise velocity) along a horizontal line through the vortex core at different streamwise locations starting from the mid-chord to a downstream area far from the trailing edge.

Figure 13a shows the distribution of pitchwise velocity, in which the black crossed symbol represents the position of the vortex center. Note that the distance between the two maxima in these velocity profiles is indicative of the vortex core size [39]. This plot clearly shows that the two maxima of the pitchwise velocity decrease as the TLV moves downstream while the size of vortex core is increased monotonically, indicating that the vorticity in the vortex core gradually decreases from mid-chord to the area far away from the trailing edge according to the Rankine vortex model. Moreover, the positive maximum of the pitchwise velocity is larger than the absolute value of the maximum negative magnitude at any streamwise location (as clearly in shown in the middle panel of Figure 8 for $z / c=1.0$ ), demonstrating that the velocity distribution in the core of the TLV is asymmetric. This can be explained by the image vortex with the same strength as the TLV rotating in the opposite direction required to satisfy the boundary conditions [40], and this image vortex induces a larger pitchwise velocity on the half of the actual vortex close to the endwall than that on the other half.

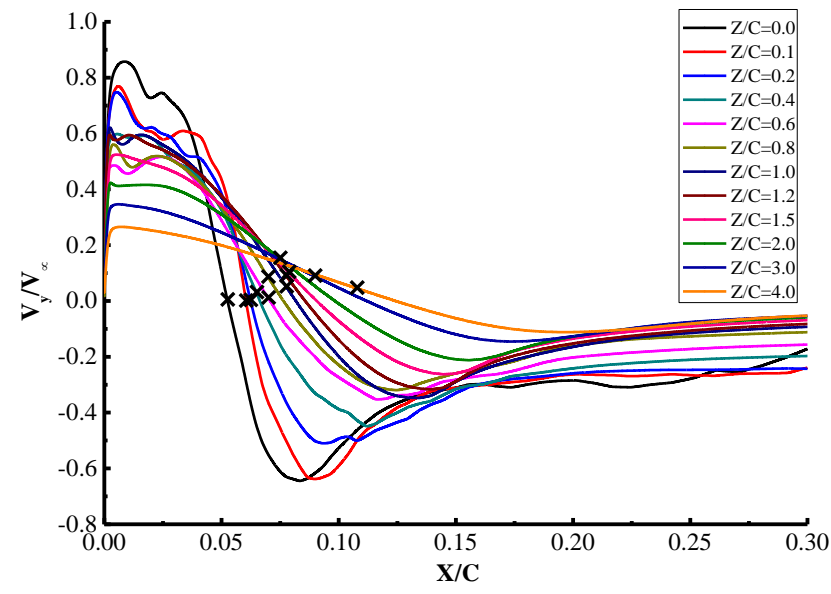

(a)

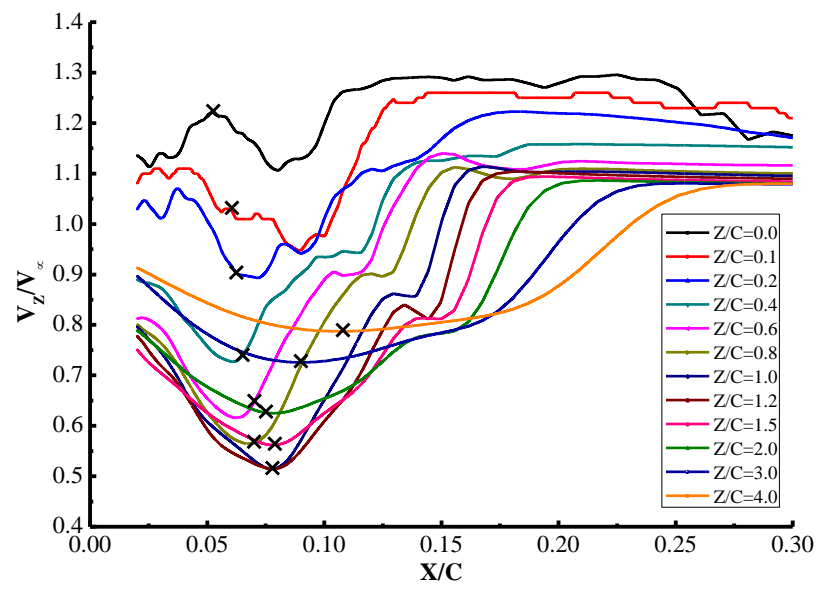

(b)

Figure 13. Distribution of velocity component along a horizontal line through vortex core: (a) Pitchwise velocity, and (b) axial velocity. 
Figure $13 \mathrm{~b}$ shows the axial velocity along the horizontal line. The axial flow in the vortex core features several interesting velocity profiles at different streamwise locations. At $z / c=0.0$ the velocity in the vortex center is a jet-like profile with a peak velocity $23 \%$ higher than the inflow velocity, and in front of this location the velocity profile is also a jet-like region which is not depicted in this Figure At $z / c=0.1$ the velocity around the vortex center approximates to the inflow velocity, while at $z / c=0.2$ the axial velocity has a small velocity deficit with a value of $0.9 V_{\infty}$ (wake-like profile) and the magnitude of this deficit further decreases to a value of about $0.5 V_{\infty}$ as the TLV moves downstream to the streamwise location at $z / c=1.2$. This progression (axial velocity profile in the vortex core changing from jet-like to wake-like) can be explained by the competition between the energy loss due to dissipation and the radial gradient in circulation strength according to Batchelor's theory [41]. As discussed in Section 3.2, the TLV in front of the mid-chord has a more concentrated structure and a higher strength than that in the downstream area, so it produces a large radial gradient in circulation strength which generates a large axial velocity in the vortex center. Opposite to the region behind the mid-chord, the strength of the TLV gradually decreases but its radius increases further. This trend results in a small radial gradient compared with the location near the leading edge, and causes the interaction between the TLV and endwall boundary layer which intensifies the energy loss due to dissipation. As a result, a wake-like profile is produced. As the TLV moves further downstream from the trailing edge, the interaction with the hydrofoil wake leads to a further decrease in axial velocity in the vortex center. In addition, the streamwise velocity in the vortex center starts to increase behind the location at $z / c=1.2$. This is because the strength of the TLV is quite small behind $z / c=1.2$, it is not able to support its structure and starts to be assimilated by the surrounding flow and eventually dissipates due to the viscous influence.

\section{Conclusions}

In this paper, the characters of the tip leakage vortex was numerically investigated by LES, and the following conclusions can be derived based on the results obtained from this study:

(1) By validation of mesh sizes, the present LES predicts well the average characteristics of the TLV when compared to the experimental data.

(2) The various vortex structures in the endwall region are identified by the mean streamlines and the region of high non-dimensional streamwise vorticity. The TLV is found to dominate the endwall vortex structures.

(3) The streamwise vorticity component dominates the vorticity field compared to the different components of vorticity, and this streamwise vorticity component is mainly produced by the spanwise derivative of the mean pitchwise velocity.

(4) During the TLV evolution, the vortex core radius keeps increasing, and its axial velocity experiences a switchover from a jet-like profile to a wake-like profile.

Author Contributions: Conceptualization, L.G. and D.Z.; methodology, L.G. and D.Z.; software, L.G. and J.C.; writing-original draft preparation, L.G.; review and editing, D.Z. and X.E.; funding acquisition, D.Z. All authors have read and agreed to the published version of the manuscript.

Funding: This research was funded by the National Natural Science Foundation of China, Grant No. 51776087, Excellent Youth Foundation of Jiangsu Scientific Committee, Grant No. BK20211547, Hydraulic Science and Technology Project of Jiangsu Province, Grant No. 2021007, and Excellent Scientific and Technological Innovation Team of College and Universities in Jiangsu Province, Grant No. SKJ(2021)-1.

Institutional Review Board Statement: Not applicable.

Informed Consent Statement: Not applicable.

Data Availability Statement: The numerical data used to support the findings of this study are included within the article. 
Conflicts of Interest: The authors declare no conflict of interest.

\section{References}

1. Denton, J.D. The 1993 IGTI Scholar Lecture: Loss Mechanisms in Turbomachines. J. Turbomach. 1993, 115, 621-656. [CrossRef]

2. Park, C.; Seol, H.; Kim, K.; Seong, W. A study on propeller noise source localization in a cavitation tunnel. Ocean Eng. 2009, 36, 754-762. [CrossRef]

3. Li, Y.S.; Cumpsty, N.A. Mixing in Axial Flow Compressors: Part I-Test Facilities and Measurements in a Four-Stage Compressor. J. Turbomach. 1991, 113, 161-165. [CrossRef]

4. Li, Y.S.; Cumpsty, N.A. Mixing in Axial Flow Compressors: Part II-Measurements in a Single Stage Compressor and a Duct. J. Mech. Des. 1990, 113, 166-174. [CrossRef]

5. Mailach, R.; Lehmann, I.; Vogeler, K. Rotating Instabilities in an Axial Compressor Originating From the Fluctuating Blade Tip Vortex. J. Turbomach. 2000, 123, 453-460. [CrossRef]

6. Rains, D.A. Tip Clearance Flows in Axial Compressors and Pumps. Ph.D. Thesis, California Institute of Technology, Pasadena, CA, USA, 2001.

7. Lakshminarayana, B.; Pouagare, M.; Davino, R. Three-Dimensional Flow Field in the Tip Region of a Compressor Rotor Passage-Part I: Mean Velocity Profiles and Annulus Wall Boundary Layer. J. Eng. Power 1982, 104, 760-771. [CrossRef]

8. Lakshminarayana, B.; Davino, R.; Pouagare, M. Three-Dimensional Flow Field in the Tip Region of a Compressor Rotor Passage-Part II: Turbulence Properties. J. Eng. Power 1982, 104, 772-781. [CrossRef]

9. Storer, J.A.; Cumpsty, N.A. Tip Leakage Flow in Axial Compressors. J. Turbomach. 1991, 113, 252-259. [CrossRef]

10. Kang, S.; Hirsch, C. Experimental Study on the Three-Dimensional Flow within a Compressor Cascade with Tip Clearance: Part I-Velocity and Pressure Fields. J. Turbomach. 1993, 115, 435-443. [CrossRef]

11. Kang, S.; Hirsch, C. Experimental Study on the Three Dimensional Flow within a Compressor Cascade with Tip Clearance: Part II-The Tip Leakage Vortex. J. Turbomach. 1992, 115, 444-452. [CrossRef]

12. Kang, S.; Hirsch, C. Tip Leakage Flow in Linear Compressor Cascade. J. Turbomach. 1994, 116, 657-664. [CrossRef]

13. Wu, H.; Miorini, R.L.; Katz, J. Measurements of the TLV structures and turbulence in the meridional plane of an axial water-jet pump. Exp. Fluids 2011, 50, 989-1003. [CrossRef]

14. Wu, H.; Tan, D.; Miorini, R.L.; Katz, J. Three-dimensional flow structures and associated turbulence in the tip region of a water-jet pump rotor blade. Exp. Fluids 2011, 51, 1721-1737. [CrossRef]

15. Wu, H.; Miorini, R.L.; Tan, D.; Katz, J. Turbulence within the Tip-Leakage Vortex of an Axial Waterjet Pump. AIAA J. 2012, 50, 2574-2587. [CrossRef]

16. Storer, J.A.; Cumpsty, N.A. An approximate analysis and prediction method for tip clearance loss in axial compressors. J. Turbomach. 1993, 116, 648-656. [CrossRef]

17. Shin, S. Reynolds-Averaged Navier-Stokes Computation of Tip Clearance Flow in a Compressor Cascade Using an Unstructured Grid. Ph.D. Thesis, Virginia Polytechnic Institute and State University, Blacksburg, VA, USA, 2001.

18. You, D.; Wang, M.; Moin, P.; Mittal, R. Effects of tip-gap size on the tip-leakage flow in a turbomachinery cascade. Phys. Fluids 2006, 18, 105102. [CrossRef]

19. You, D.; Wang, M.; Moin, P.; Mittal, R. Large-eddy simulation analysis of mechanisms for viscous losses in a turbomachinery tip-clearance flow. J. Fluid Mech. 2007, 586, 177-204. [CrossRef]

20. Gaggero, S.; Tani, G.; Viviani, M.; Conti, F. A study on the numerical prediction of propellers cavitating tip vortex. Ocean Eng. 2014, 92, 137-161. [CrossRef]

21. Zhang, D.; Shi, W.; van Esch, B.B.; Shi, L.; Dubuisson, M. Numerical and experimental investigation of TLV trajectory and dynamics in an axial flow pump. Comput. Fluids 2015, 112, 61-71. [CrossRef]

22. Zhang, D.; Shi, L.; Shi, W.; Zhao, R.; Wang, H.; Esch, B.P.M.V. Numerical analysis of unsteady TLV cavitation cloud and unstable suction-side-perpendicular cavitating vortices in an axial flow pump. Int. J. Multiph. Flow 2015, 77, 244-259. [CrossRef]

23. Higashi, S.; Yoshida, Y.; Tsujimoto, Y. Tip leakage vortex cavitation from the tip clearance of a single hydrofoil. JSME Int. J. 2002, 45, 662-671. [CrossRef]

24. Murayama, M. Unsteady tip leakage vortex cavitation originating from the tip clearance of an oscillating hydrofoil. J. Fluids Eng. 2006, 128, 421-429. [CrossRef]

25. Dreyer, M. Mind The Gap: Tip Leakage Vortex Dynamics and Cavitation in Axial Turbines. Ph.D. Thesis, EPFL, Lausanne, Switzerland, 2015.

26. Zwart, P.J.; Gerber, A.G.; Belamri, T. A two-phase flow model for predicting cavitation dynamics. In Proceedings of the Fifth International Conference on Multiphase Flow, Yokohama, Japan, 30 May-4 June 2004; Volume 152.

27. Mejri, I.; Bakir, F.; Rey, R.; Belamri, T.; Mejri, I. Comparison of computational results obtained from a homogeneous cavitation model with experimental investigations of three inducers. J. Fluids Eng. 2006, 128, 1308-1323. [CrossRef]

28. Luo, X.; Ji, B.; Peng, X.; Xu, H.; Nishi, M. Numerical simulation of cavity shedding from a three-dimensional twisted hydrofoil and induced pressure fluctuation by large-eddy simulation. J. Fluids Eng. 2012, 134, 041202. [CrossRef]

29. Germano, M.; Piomelli, U.; Moin, P.; Cabot, W.H. A dynamic subgrid-scale eddy viscosity model. Phys. Fluids A Fluid Dyn. 1991, 3, 1760-1765. [CrossRef] 
30. Lilly, D.K. A proposed modification of the germano subgrid-scale closure method. Phys. Fluids A Fluid Dyn. 1992, 4, 633-635. [CrossRef]

31. Pope, S.B. Turbulent flows. Turbul. Flows 2001, 10, 806. [CrossRef]

32. Beaudan, P.; Moin, P. Numerical Experiments on the Flow Past a Circular Cylinder at Sub-Critical Reynolds Number (No. TF-62). Ph.D. Thesis, Stanford University, Stanford, CA, USA, 1995.

33. Mittal, R.; Moin, P. Suitability of upwind-biased finite difference schemes for large-eddy simulation of turbulent flows. AIAA J. 1997, 35, 1415-1417. [CrossRef]

34. You, D.; Mittal, R.; Moin, P.; Wang, M. Computational methodology for large-eddy simulation of tip-clearance flows. AIAA J. 2004, 42, 271-279. [CrossRef]

35. Lee, T.; Pereira, J. Nature of wakelike and jetlike axial tip vortex flows. J. Aircr. 2010, 47, 1946-1954. [CrossRef]

36. Laborde, R.; Chantrel, P.; Mory, M. Tip clearance and tip vortex cavitation in an axial flow pump. J. Fluids Eng. 1997, 119, 680-685. [CrossRef]

37. Decaix, J.; Balarac, G.; Dreyer, M.; Farhat, M.; Munch, C. RANS and LES computations of the tip-leakage vortex for different gap widths. J. Turbul. 2015, 16, 309-341. [CrossRef]

38. Doligalski, T.L.; Smith, C.R.; Walker, J.D.A. Vortex interactions with walls. Annu. Rev. Fluid Mech. 1994, 26, 573-616. [CrossRef]

39. Ghias, R.; Mittal, R.; Dong, H.; Lund, T. Study of tip-vortex formation using large-eddy simulation. AIAA J. 2005, 1280, 1-13.

40. Chen, G.T.; Greitzer, E.M.; Tan, C.S.; Marble, F.E. Similarity analysis of compressor tip clearance flow structure. J. Turbomach. 1991, 113, 260-271. [CrossRef]

41. Anderson, E.A.; Lawton, T.A. Correlation between Vortex Strength and Axial Velocity in a Trailing Vortex. J. Aircr. 2003, 40, 699-704. [CrossRef] 